\title{
The phenotype of concurrent chronic bronchitis and frequent exacerbations in patients with severe COPD attending Swedish secondary care units
}

This article was published in the following Dove Press journal: International Journal of COPD

28 October 2015

Number of times this article has been viewed

\author{
Josefin Sundh' \\ Gunnar Johansson ${ }^{2}$ \\ Kjell Larsson ${ }^{3}$ \\ Anders Lindén ${ }^{3}$ \\ Claes-Göran Löfdahl ${ }^{4}$ \\ Thomas Sandström ${ }^{5}$ \\ Christer Janson ${ }^{6}$
}

'Department of Respiratory Medicine, Örebro University, Örebro, Sweden;

${ }^{2}$ Department of Public Health and Caring Science, Family Medicine and Preventive Medicine, Uppsala University, Uppsala, Sweden; ${ }^{3}$ Unit for Lung and Airway Research, Institute of Environmental Medicine, Karolinska Institutet, Stockholm, Sweden;

${ }^{4}$ Department of Respiratory Medicine and Allergology, Lund University, Lund, Sweden; ${ }^{5}$ Department of Public Health and Clinical Medicine, Division of Medicine/Respiratory Medicine, Umeå University, Umeå, Sweden; ${ }^{6}$ Department of Medical Sciences, Respiratory, Allergy and Sleep Research, Uppsala University, Uppsala, Sweden
Correspondence: Josefin Sundh Department of Respiratory Medicine, Örebro University, 70I85 Örebro, Sweden

$\mathrm{Tel}+46702349517$

Fax +46 I9 I86526

Email josefin.sundh@oru.se
Background: Chronic bronchitis and previous exacerbations are both well-known risk factors for new exacerbations, impaired health-related quality of life, and increased mortality in COPD. The aim of the study was to characterize the phenotype of concurrent chronic bronchitis and frequent exacerbation in severe COPD.

Methods: Information on patient characteristics, comorbidity, and exacerbations from the previous year (total number and number requiring hospitalization) was collected from 373 patients with stage III and IV COPD attending 27 secondary care respiratory units in Sweden. Logistic regression used chronic bronchitis and frequent exacerbations ( $\geq 2$ exacerbations or $\geq 1$ hospitalized exacerbations in the previous year) as response variables. Stratification and interaction analyses examined effect modification by sex.

Results: Chronic bronchitis was associated with current smoking (adjusted odds ratio [OR] [95\% CI], 2.75 [1.54-4.91]; $P=0.001$ ), frequent exacerbations (OR [95\% CI], 1.93 [1.24-3.01]; $P=0.004$ ), and musculoskeletal symptoms (OR [95\% CI], 1.74 [1.05-2.86]; $P=0.031$ ), while frequent exacerbations were associated with lung function (forced expiratory volume in 1 second as a percentage of predicted value $\left[\mathrm{FEV}_{1} \%\right.$ pred]) $(\mathrm{OR}[95 \% \mathrm{CI}] 0.96[0.94-0.98] ; P=0.001)$ and chronic bronchitis (OR [95\% CI] 1.73 [1.11-2.68]; $P=0.015)$. The phenotype with both chronic bronchitis and frequent exacerbations was associated with $\mathrm{FEV}_{1} \%$ pred $(\mathrm{OR}[95 \% \mathrm{CI}]$ 0.95 [0.92-0.98]; $P=0.002$ ) and musculoskeletal symptoms (OR [95\% CI] 2.55 [1.31-4.99]; $P=0.006)$. The association of smoking with the phenotype of chronic bronchitis and exacerbations was stronger in women than in men (interaction, $P=0.040$ ).

Conclusion: Musculoskeletal symptoms and low lung function are associated with the phenotype of combined chronic bronchitis and frequent exacerbations in severe COPD. In women, current smoking is of specific importance for this phenotype. This should be considered in clinical COPD care.

Keywords: lung function, smoking, chronic obstructive lung disease, musculoskeletal symptoms

\section{Introduction}

In the Global Initiative for Chronic Obstructive Lung Disease (GOLD) recommendations, chronic bronchitis is defined as an independent disease entity with cough and sputum production for at least 3 months in 2 consecutive years, which may exist in patients with normal spirometry or may be associated with development of a fixed airflow limitation, as in chronic obstructive pulmonary disease (COPD). ${ }^{1}$ However, not all patients with COPD have chronic bronchitis. In COPD, concurrent chronic bronchitis is associated with more rapid decline in lung function, ${ }^{2}$ more frequent exacerbations, ${ }^{3}$ hospital admissions, ${ }^{4}$ worse health-related quality of life (HRQL), ${ }^{5}$ and increased 
mortality risk. ${ }^{6,7}$ In addition, exacerbations per se are known to increase lung function decline over time ${ }^{8}$ and to increase frequency of hospital admissions, ${ }^{9}$ thereby generating a substantial financial burden for society. ${ }^{10}$ Exacerbations are also known to deteriorate quality of life $\mathrm{e}^{11,12}$ and to increase the risk of mortality. ${ }^{9,13,14}$

Recently, attention has been paid to the specific COPD phenotype of combined chronic bronchitis and frequent exacerbations, ${ }^{15}$ which is associated with high health care costs and resource utilization ${ }^{16}$ and high mortality. ${ }^{7}$ This phenotype of COPD has also been forwarded as a subgroup, where specific pharmacological treatment could reduce exacerbation risk. ${ }^{17,18}$

The aim of this study was to further characterize clinical factors, which are associated with the phenotype of severe COPD, with concurrent chronic bronchitis and frequent exacerbations. An additional aim was to discover if the factors associated with this phenotype differ by sex.

\section{Methods}

\section{Data collection}

Sweden has 33 hospital-based secondary care respiratory units, including departments of respiratory medicine or sections of respiratory medicine within departments of internal medicine. All 33 units were invited to participate in the present study. ${ }^{5}$ Each respiratory unit was asked to consecutively enroll a maximum of ten patients with GOLD grade III COPD and five patients with GOLD grade IV $\mathrm{COPD}^{1}$ during the period from May 12, 2011 to March 28, 2012, approximately matching the distribution of severe and very severe COPD in the general population. ${ }^{19,20}$ The only exclusion criterion was an inability to complete the study on language grounds. During the patients' visits, the physician responsible for the study center collected information on sex, age, smoking history and habits, body weight and height, influenza and pneumococcal vaccination status, current pharmacological treatment, number of exacerbations, and health care visits within the past year, symptoms indicating chronic bronchitis, and presence of cardiovascular disease, diabetes, renal impairment, malnutrition, obesity/overweight, musculoskeletal symptoms, osteoporosis, or depression. Chronic bronchitis was defined as the presence of productive cough for 3 months in 2 successive years. ${ }^{1}$ The other comorbid conditions were defined as the doctor's diagnosis, combined with pharmacological or non-pharmacological treatment of the condition. Musculoskeletal symptoms included clinical signs of muscle weakness, or ache or discomfort severe enough to constitute the basis for maintenance treatment with medication or physiotherapy. Total number of exacerbations and number of exacerbations causing hospitalizations were noted. An exacerbation was defined as a worsening of symptoms of dyspnea and sputa beyond normal day-today variation, requiring increased maintenance treatment, courses of antibiotics, or oral steroids, or an emergency visit, or hospitalization. ${ }^{9}$

Patient information was entered in the study case record form together with data from the most recently performed spirometry. Post-bronchodilator values were used, but were substituted with pre-bronchodilator values if post-bronchodilator values were missing. The patients were classified according to $\mathrm{GOLD}^{1}$ as COPD stage III (forced expiratory volume in 1 second as a percentage of predicted value $\left[\mathrm{FEV}_{1} \%\right.$ pred], 30-49) or COPD stage IV ( $\mathrm{EV}_{1} \%$ pred $<30$ or $<50$ with concomitant hypoxia). Body mass index (BMI) was calculated and classified into groups defined as BMI 22 or less, BMI more than 22 but less than 31, and BMI 31 or more. Frequent exacerbations were defined as having two or more exacerbations or one or more hospitalizations due to COPD exacerbations in the most recent year. ${ }^{1}$ Based on these criteria, the patients were categorized into four groups: 1) no chronic bronchitis or frequent exacerbations; 2) frequent exacerbations but no chronic bronchitis; 3 ) chronic bronchitis but no frequent exacerbations; and 4) chronic bronchitis and frequent exacerbations. The outcomes of primary interest were the associations with the category of concurrent chronic bronchitis and frequent exacerbations.

\section{Statistics}

Statistical analyses were performed using IBM Statistics SPSS version 22.0 (IBM Corporation, Armonk, NY, USA). Student's $t$-test was used to investigate differences in continuous variables and the $\chi^{2}$ test was used to investigate differences in categorical variables. Binary logistic regression analyses with chronic bronchitis and respectively frequent exacerbations as response variables were performed. Multinominal regression was used when the response variable included the four categories related to chronic bronchitis and frequent exacerbations. Univariate regression analyses examined the potential explanatory variables of sex, age, $\mathrm{FEV}_{1} \%$ pred, current smoking status, BMI (three groups), cardiovascular disease, diabetes, renal impairment, musculoskeletal symptoms, osteoporosis, depression, and in the binary logistic regression, frequent exacerbations and respectively chronic bronchitis. No a priori assumptions were made, and 
thus, multivariate logistic regression analyses included variables with statistically significant associations in univariate logistic regression. The multivariate logistic regression model was repeated with adjustment for treatment with long-acting muscarinic antagonists and/or combined long-acting beta-2agonists and inhalation corticosteroids, and with adjustment for vaccinations. To investigate differences between male and female patients, the multinominal multivariate logistic regression model analysis was performed stratified by sex. Separate interaction analysis investigated potential modification of effect by sex, using interaction terms for this variable with the explanatory variables included in the multivariate analysis. In all analyses, a $P$-value below 0.05 was considered statistically significant.

\section{Ethics}

The current study was conducted as a non-interventional trial, in accordance with EU directive 2001/20/EC and the Declaration of Helsinki. The study protocol was reviewed and approved by the Regional Ethical Review Board of Umeå University (Dnr 2011-10-31M). Written consent was given by all patients.

\section{Results Data collection}

In total, data were collected from 383 patients. Of these, ten patients did not fulfill the inclusion criterion of a $\mathrm{FEV}_{1}$ below $50 \%$ of predicted value and were excluded from further analyses. Post-bronchodilator values were missing for 161 patients, and were replaced with pre-bronchodilator values.

\section{Patient characteristics}

Patient characteristics, distributed on having chronic bronchitis or not, and frequent exacerbations or not, are presented in Table 1. In summary, patients with chronic bronchitis were more often current smokers, had frequent exacerbations, and had musculoskeletal symptoms, compared with those without chronic bronchitis. Patients with frequent exacerbations more often had COPD stage IV, chronic bronchitis, diabetes, and musculoskeletal symptoms than those patients with infrequent exacerbations.

Of the patients, $35.7 \%$ had neither chronic bronchitis nor frequent exacerbations, $27.3 \%$ had frequent exacerbations but no chronic bronchitis, $15.0 \%$ had chronic bronchitis but

Table I Patient characteristics by chronic bronchitis and frequent exacerbations

\begin{tabular}{|c|c|c|c|c|c|c|}
\hline \multirow[t]{2}{*}{ Patient characteristics } & \multicolumn{2}{|c|}{ Chronic bronchitis } & \multirow[t]{2}{*}{$P$-value } & \multicolumn{2}{|c|}{ Frequent exacerbations } & \multirow[t]{2}{*}{$P$-value } \\
\hline & No $(n=235)$ & Yes $(n=138)$ & & No $(n=189)$ & Yes $(n=184)$ & \\
\hline \multicolumn{7}{|l|}{ Sex } \\
\hline Male & 105 (44.7\%) & $60(43.5 \%)$ & Ref & 99 (52.4\%) & $109(59.2 \%)$ & Ref \\
\hline Female & I 30 (55.3\%) & 78 (56.5\%) & 0.821 & $90(47.6 \%)$ & 75 (40.8\%) & 0.182 \\
\hline Age & $71.2( \pm 8.31)$ & $71.3( \pm 7.02)$ & 0.919 & $71.2( \pm 7.79)$ & $71.3( \pm 7.93)$ & 0.938 \\
\hline \multicolumn{7}{|l|}{ Smoking habits } \\
\hline Never or ex-smoker & 209 (88.9\%) & $103(74.6 \%)$ & Ref & I55 (82.0\%) & $156(85.2 \%)$ & Ref \\
\hline Current smoker & 26 (II.1\%) & $35(25.4 \%)$ & $<0.0001$ & $34(18.0 \%)$ & $27(14.7 \%)$ & 0.399 \\
\hline \multicolumn{7}{|l|}{ COPD stage } \\
\hline III & 170 (72.3\%) & $89(64.5 \%)$ & Ref & 150 (79.4\%) & 109 (59.2\%) & Ref \\
\hline IV & $65(27.7 \%)$ & 49 (35.5\%) & 0.112 & $39(20.6 \%)$ & $75(40.8 \%)$ & $<0.0001$ \\
\hline FEV $\%$ pred & $35.2( \pm 8.57)$ & $34.0( \pm 8.87)$ & 0.176 & $56(29.6 \%)$ & $82(44.6 \%)$ & 0.003 \\
\hline \multicolumn{7}{|l|}{ Body mass index } \\
\hline$\leq 22.0$ & $66(28.1 \%)$ & $48(34.8 \%)$ & 0.155 & $50(26.5 \%)$ & $64(34.8 \%)$ & 0.155 \\
\hline$>22.0, \leq 30.0$ & $139(59.1 \%)$ & $72(52.2 \%)$ & Ref & 110 (58.2\%) & I0I (54.9\%) & Ref \\
\hline$>30.0$ & 30 (12.8\%) & $18(13.0 \%)$ & 0.658 & $29(15.3 \%)$ & $19(10.3 \%)$ & 0.300 \\
\hline Frequent exacerbations & $102(43.4 \%)$ & $82(59.4 \%)$ & 0.003 & - & - & - \\
\hline Chronic bronchitis & - & - & - & $52(29.6 \%)$ & II 4 (44.6\%) & 0.003 \\
\hline Cardiovascular disease & 140 (59.6\%) & $83(60.1 \%)$ & 0.914 & $109(57.7 \%)$ & II 4 (62.0\%) & 0.399 \\
\hline Diabetes & $23(9.8 \%)$ & 17 (I2.3\%) & 0.446 & $20(10.6 \%)$ & $20(10.9 \%)$ & 0.928 \\
\hline Renal impairment & $9(3.8 \%)$ & $5(3.6 \%)$ & 0.919 & 7 (3.7\%) & 7 (3.8\%) & 0.959 \\
\hline Musculoskeletal symptoms & 45 (19.1\%) & $45(32.6 \%)$ & 0.003 & $36(19.0 \%)$ & $54(29.3 \%)$ & 0.020 \\
\hline Osteoporosis & 57 (24.3\%) & $46(33.3 \%)$ & 0.058 & $43(22.8 \%)$ & $60(32.6 \%)$ & 0.033 \\
\hline Depression & $33(14.0 \%)$ & $29(21.0 \%)$ & 0.081 & 27 (I4.3\%) & 35 (I9.0\%) & 0.219 \\
\hline
\end{tabular}

Note: Data presented as numbers (\%) of characteristics or mean ( \pm standard deviations) as compared with the remaining study population. Abbreviations: $\mathrm{n}$, number of patients; $\mathrm{FEV}_{1} \%$ pred, forced expiratory volume in I second as a percentage of predicted value; Ref, reference. 


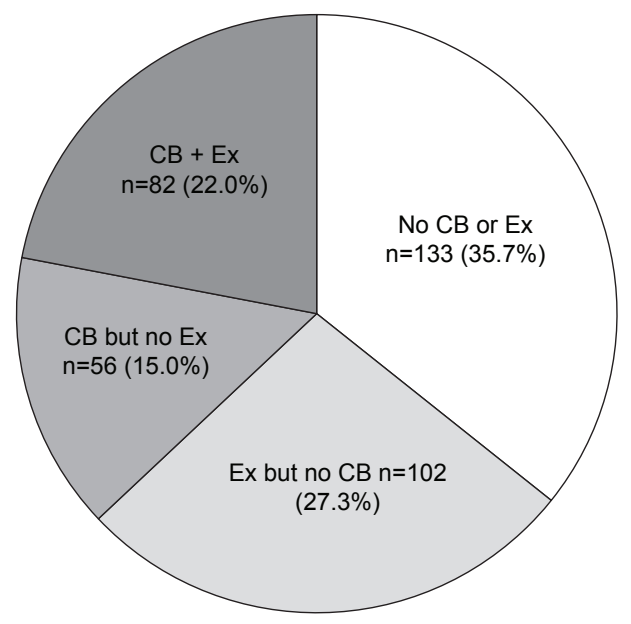

Figure I Categories of the response variable in multi-nominal logistic regression. Note: Data presented as numbers (percentages) of the total study population. Abbreviations: $\mathrm{CB}$, chronic bronchitis; Ex, frequent exacerbations; No $\mathrm{CB}$ or Ex, no chronic bronchitis and no frequent exacerbations; $C B+E x$, both chronic bronchitis and frequent exacerbations.

not frequent exacerbations, and $22.0 \%$ had the phenotype of both chronic bronchitis and frequent exacerbations (Figure 1). Patients with frequent exacerbations but no chronic bronchitis had COPD stage IV more often compared with the reference group of patients with no chronic bronchitis and no frequent exacerbations. Patients with chronic bronchitis without frequent exacerbations were more likely to be current smokers, and patients with combined chronic bronchitis and frequent exacerbations more often had COPD stage IV, musculoskeletal symptoms, and osteoporosis (Figure 2).

\section{Logistic regression analyses}

The main results of the binary logistic regression analyses are presented in Table 2. Current smoking, frequent exacerbations, and musculoskeletal symptoms were associated with chronic bronchitis, whereas $\mathrm{FEV}_{1} \%$ pred and chronic bronchitis were associated with frequent exacerbations. The main results of the multinominal logistic regression analyses are presented in Table 3 and Figure 3. Current smoking was associated with having chronic bronchitis without frequent exacerbations. Lower $\mathrm{FEV}_{1} \%$ pred and musculoskeletal symptoms were associated with the combined phenotype of chronic bronchitis and frequent exacerbations. The results of the binary and multinominal logistic regression analyses did not change considerably with further adjustment for maintenance therapy or vaccination status (data not shown).

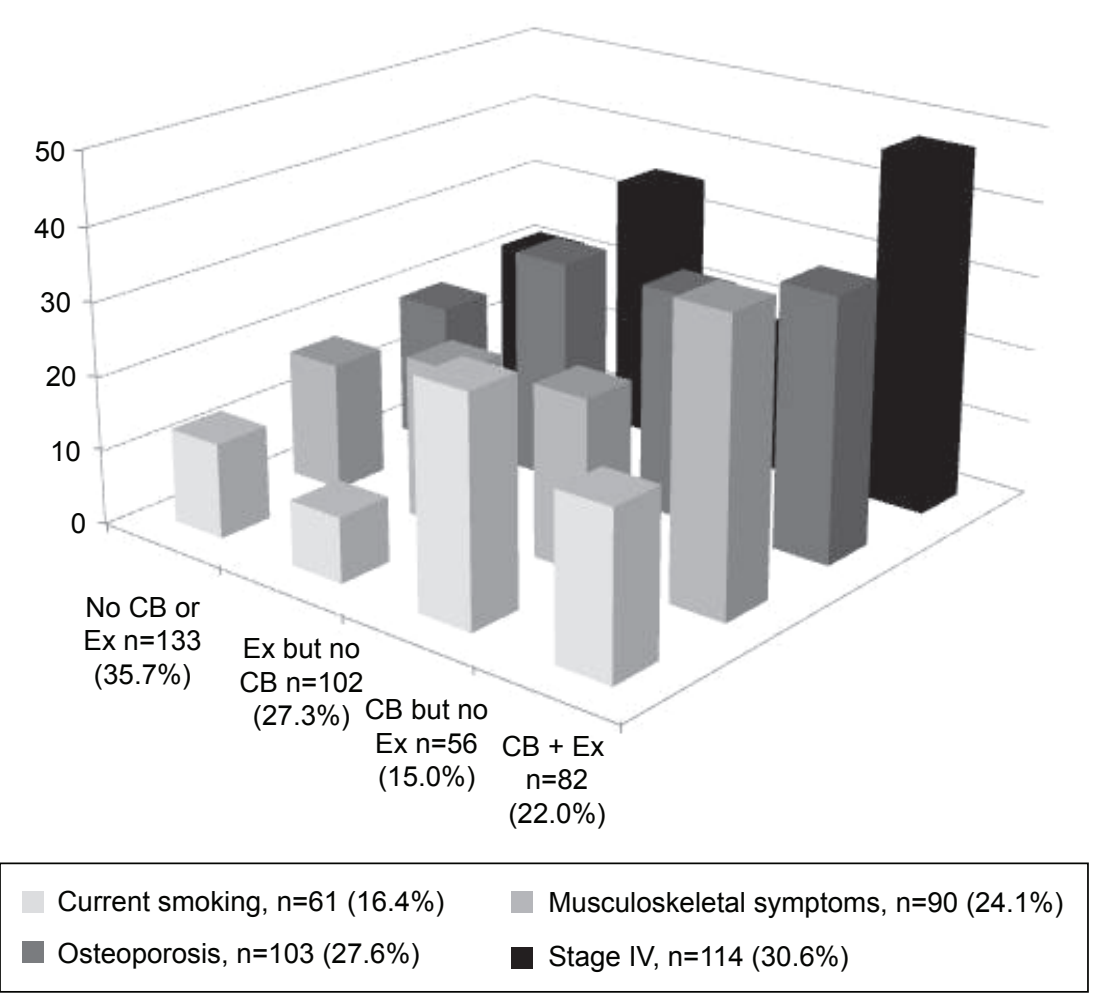

Figure 2 Clinical characteristics in different phenotypes.

Note: Proportion of clinical characteristics in different phenotypes, expressed as percentages.

Abbreviations: $\mathrm{CB}$, chronic bronchitis; $\mathrm{Ex}$, frequent exacerbations; No $\mathrm{CB}$ or $\mathrm{Ex}$, no chronic bronchitis and no frequent exacerbations; $\mathrm{CB}+\mathrm{Ex}$, both chronic bronchitis and frequent exacerbations. 
Table 2 Logistic regression analyses

\begin{tabular}{|c|c|c|c|c|}
\hline \multirow[t]{2}{*}{ Explanatory variables } & Chronic bronchitis & $P$-value & Chronic bronchitis & $P$-value \\
\hline & \multicolumn{2}{|l|}{ Unadjusted OR $(95 \% \mathrm{Cl})$} & \multicolumn{2}{|l|}{ Adjusted OR (95\% Cl) } \\
\hline Current smoker & $2.73(1.56-4.78)$ & $<0.000$ I & $2.75(1.54-4.9 \mid)$ & 0.001 \\
\hline Frequent exacerbations & $1.91(1.25-2.93)$ & 0.003 & $1.93(1.24-3.01)$ & 0.004 \\
\hline \multirow[t]{3}{*}{ Musculoskeletal symptoms } & $2.04(1.26-3.31)$ & 0.004 & $1.74(1.05-2.86)$ & 0.031 \\
\hline & Frequent exacerbations & $P$-value & Frequent exacerbations & P-value \\
\hline & \multicolumn{2}{|l|}{ Unadjusted OR (95\% CI) } & \multicolumn{2}{|l|}{ Adjusted OR (95\% Cl) } \\
\hline $\mathrm{FEV}, \%$ pred & $0.96(0.93-0.98)$ & $<0.0001$ & $0.96(0.94-0.98)$ & 0.001 \\
\hline Chronic bronchitis & $1.91(1.25-2.93)$ & 0.003 & $1.73(1.11-2.68)$ & 0.015 \\
\hline Musculoskeletal symptoms & $1.77(1.09-2.86)$ & 0.021 & I.5I (0.9I-2.53) & 0.114 \\
\hline Osteoporosis & $1.64(1.04-2.60)$ & 0.034 & $1.29(0.79-2.10)$ & 0.314 \\
\hline
\end{tabular}

Note: In the multivariate analyses, all variables with a statistically significant association in the univariate analyses were included and presented in the table.

Abbreviations: OR, odds ratio; $\mathrm{Cl}$, confidence interval; $\mathrm{FEV} \%$ pred, forced expiratory volume in I second as a percentage of predicted value.

\section{Sex differences}

The multivariate multinominal regression analyses stratified by sex are shown in Table 4. In men, lower $\mathrm{FEV}_{1} \%$ pred was associated with the combined phenotype of chronic bronchitis and frequent exacerbations. In women, current smoking and osteoporosis were associated with chronic bronchitis without frequent exacerbations, and current smoking and musculoskeletal symptoms were associated with chronic bronchitis and frequent exacerbations. The interaction analyses showed that the association of musculoskeletal symptoms in patients with chronic bronchitis but no frequent exacerbations, and the association of current smoking with the combined phenotype of chronic bronchitis and frequent exacerbations, was stronger in women than in men (Table 4).

\section{Discussion}

The most important finding in our study is that the phenotype of having both chronic bronchitis and frequent exacerbations is characterized by lower lung function and musculoskeletal symptoms. We find it interesting that musculoskeletal symptoms were associated with chronic bronchitis and with the phenotype of chronic bronchitis and frequent exacerbations. We are not aware of any previous study showing the association of musculoskeletal symptoms with these phenotypes.

For practical reasons, we defined musculoskeletal symptoms as a doctor's diagnosis of muscle weakness, or muscle ache or discomfort enough to cause maintenance treatment with medication or physiotherapy. Skeletal muscle dysfunction as measured by quadriceps strength is prevalent in approximately a third of all COPD patients, increasing by disease severity. ${ }^{21}$ Indeed, the updated American Thoracic Society/European Respiratory Society (ATS/ERS) statement on limb muscle dysfunction in COPD emphasizes that muscle dysfunction influences physical activity, exercise tolerance, quality of life, and mortality. ${ }^{22}$ Several pathophysiological explanations for musculoskeletal dysfunction in COPD have been suggested, and the underlying cause is often multifactorial. Reduced activity, malnutrition, systemic steroids, hormone imbalance, hypoxia, oxidative stress, and inflammation can all lead to muscle weakness. ${ }^{22,23}$ It is known that several proinflammatory cytokines can cause catabolism and muscle atrophy in chronic diseases..$^{24}$ Moreover, systemic inflammation, as assessed by highly sensitive C-reactive protein, fibrinogen, and interleukin-6 in blood, is associated with a decreased level of physical activity in COPD, possibly indicating that

Table 3 Multinominal regression

\begin{tabular}{|c|c|c|c|c|c|c|c|}
\hline Variables & $\begin{array}{l}\text { No chronic bronchitis, } \\
\text { no frequent } \\
\text { exacerbations } \\
(n=133)\end{array}$ & $\begin{array}{l}\text { No chronic bronchitis, } \\
\text { but frequent } \\
\text { exacerbations } \\
(n=102)\end{array}$ & $P$-value & $\begin{array}{l}\text { Chronic bronchitis, } \\
\text { but no frequent } \\
\text { exacerbations } \\
(n=56)\end{array}$ & $P$-value & $\begin{array}{l}\text { Chronic bronchitis, } \\
\text { and frequent } \\
\text { exacerbations } \\
(n=82)\end{array}$ & $P$-value \\
\hline Current smoker & Ref & $0.67(0.28-1.58)$ & 0.359 & $2.94(1.35-6.39)$ & 0.006 & $1.84(0.86-3.94)$ & 0.115 \\
\hline $\mathrm{FEV}_{1} \%$ pred & Ref & $0.97(0.94-1.00)$ & 0.079 & I.0I (0.97-I.05) & 0.617 & $0.95(0.92-0.98)$ & 0.002 \\
\hline $\begin{array}{l}\text { Musculoskeletal } \\
\text { symptoms }\end{array}$ & Ref & $1.20(0.6 \mathrm{I}-2.37)$ & 0.600 & $1.08(0.48-2.42)$ & 0.858 & $2.55(1.31-4.99)$ & 0.006 \\
\hline Osteoporosis & Ref & $1.60(0.85-3.00)$ & 0.142 & $1.82(0.86-3.84)$ & 0.116 & $1.59(0.82-3.10)$ & 0.172 \\
\hline
\end{tabular}

Note: In the multivariate analysis, all variables with a statistically significant association in the univariate analyses were included and presented in the table. Data are presented as adjusted OR $(95 \% \mathrm{Cl})$.

Abbreviations: OR, odds ratio; $\mathrm{Cl}$, confidence interval; $\mathrm{FEV}, \%$ pred, forced expiratory volume in I second as a percentage of predicted value; Ref, reference. 


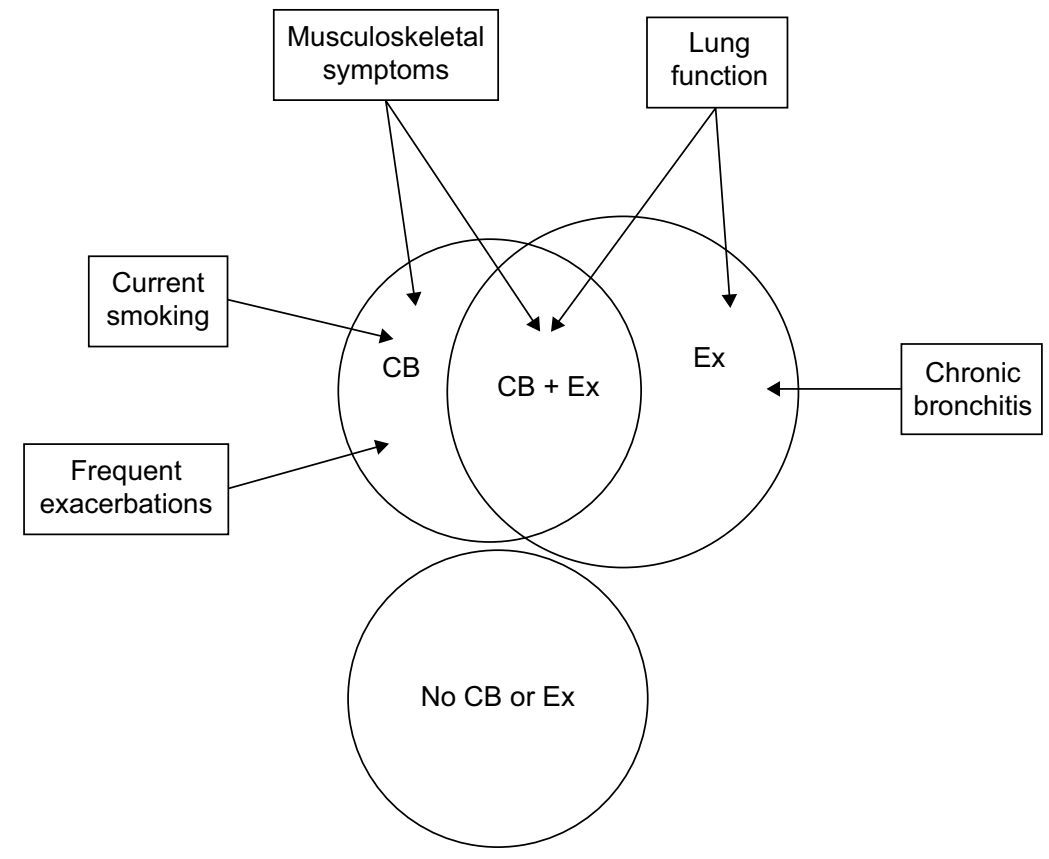

Figure 3 COPD phenotypes and patient characteristics.

Note: Venn diagram showing the proportional distribution of different phenotypes in the study population, and the associations of different patient characteristics in logistic regression analyses.

Abbreviations: $C B$, chronic bronchitis; $E x$, frequent exacerbations; No $C B$ or $E x$, no chronic bronchitis and no frequent exacerbations; $C B+E x$, both chronic bronchitis and frequent exacerbations.

inflammation in itself could initiate muscle dysfunction. ${ }^{25,26}$ Muscle fatigue has also been shown to be more pronounced in smokers than in ex-smokers, ${ }^{27}$ which supports the hypothesis of active inflammation as an important explanation to muscle dysfunction in COPD.

The second most important finding in our current study was that current smoking appears to increase the likelihood of having the phenotype with the combination of chronic bronchitis and frequent exacerbations in women but not in men. Female sex is known to be an independent risk factor for having frequent exacerbations, ${ }^{7}$ but to our knowledge, sex differences in how other risk factors influence the risk of chronic bronchitis and frequent exacerbations have not been discussed previously.
Women seem to be more sensitive to a given amount of tobacco smoke exposure, ${ }^{28}$ and in addition, estradiol-mediated differences in tobacco-smoke metabolism by up-regulation of cytochrome P450 enzymes have been suggested. ${ }^{29}$

Our results also confirm the previous well-known association between chronic bronchitis and exacerbations in COPD, ${ }^{3,7,30,31}$ and the fact that frequent exacerbations are mainly influenced by lower lung function, ${ }^{7}$ and that chronic bronchitis is mainly influenced by current smoking. ${ }^{3}$ However, our study adds yet one more clinical dimension by emphasizing the phenotype of having the combination of chronic bronchitis and frequent exacerbations. The group of patients with this phenotype constitutes a minority of the study

Table 4 Sex differences in multinominal regression

\begin{tabular}{|c|c|c|c|c|c|}
\hline Explanation variables & $\begin{array}{l}\text { Male } \\
\text { Adjusted OR }(95 \% \mathrm{CI})\end{array}$ & P-value & $\begin{array}{l}\text { Female } \\
\text { Adjusted OR }(95 \% \mathrm{CI})\end{array}$ & P-value & $\begin{array}{l}P \text {-value } \\
\text { interaction }\end{array}$ \\
\hline \multicolumn{6}{|c|}{ Both chronic bronchitis and frequent exacerbations } \\
\hline Current smoker & $0.65(0.19-2.28)$ & 0.502 & $3.86(I .3|-| I .4)$ & 0.015 & 0.040 \\
\hline $\mathrm{FEV} \%$ pred & $0.91(0.86-0.96)$ & 0.001 & $0.97(0.93-1.02)$ & 0.202 & 0.075 \\
\hline Musculoskeletal symptoms & $2.74(0.86-8.77)$ & 0.090 & $2.45(1.06-5.66)$ & 0.036 & 0.810 \\
\hline Osteoporosis & I. $19(0.32-4.42)$ & 0.798 & $1.91(0.85-4.32)$ & 0.120 & 0.275 \\
\hline \multicolumn{6}{|c|}{ Chronic bronchitis but no frequent exacerbations } \\
\hline Current smoker & $2.47(0.86-7.1 I)$ & 0.095 & $4.28(1.26-\mid 4.5)$ & 0.020 & 0.339 \\
\hline FEV $\%$ pred & $1.01(0.95-1.07)$ & 0.812 & $1.01(0.96-1.07)$ & 0.741 & 0.972 \\
\hline Musculoskeletal symptoms & $0.20(0.02-I .74)$ & 0.144 & $2.13(0.78-5.80)$ & 0.139 & 0.028 \\
\hline Osteoporosis & $0.68(0.13-3.68)$ & 0.657 & $3.25(1.23-8.64)$ & 0.018 & 0.474 \\
\hline
\end{tabular}

Note: Results from multi-nominal multivariate regression analyses stratified by sex.

Abbreviations: $\mathrm{OR}$, odds ratio; $\mathrm{Cl}$, confidence interval; $\mathrm{FEV}$ \% pred, forced expiratory volume in I second as a percentage of predicted value. 
population, approximately a fifth in our study. Nevertheless, the combined phenotype contributes to higher health care costs, higher resource utilization, ${ }^{16}$ and increased mortality, ${ }^{7}$ which motivates a focus on optimizing COPD care in this specified subgroup. Interestingly, special attention has been given to add-on treatment to COPD patients with chronic bronchitis and frequent exacerbations, where the PDE4 inhibitor roflumilast has been shown to reduce hospitalized exacerbations. ${ }^{18}$ Another possibility might be maintenance therapy with macrolides for reduction of exacerbation frequency. ${ }^{32}$ However, more studies are needed to further explore the target group and the long-term effects.

A strength of the current investigation is that it is a multicenter study of patients from almost all the secondary care respiratory units in Sweden with data on important clinical factors including several comorbid conditions. A potential limitation is that the comorbid conditions were defined as demanding pharmacological or non-pharmacological treatment of the specific comorbid condition. Hypothetically, this could mean that milder forms of symptoms related to the comorbid conditions have been overlooked. In addition, the term musculoskeletal symptoms could cover a variety of conditions of different character. However, the fact that the definition was based on a doctor's diagnosis combined with pharmacological or non-pharmacological treatment should ensure that only clinically relevant conditions were involved. Future studies should be directed to characterize the musculoskeletal symptoms in greater detail, and should also include measures of muscle strength or physical capacity.

\section{Conclusion}

Lower lung function and musculoskeletal symptoms are associated with the phenotype of chronic bronchitis and frequent exacerbations in patients with severe COPD. In women, unlike in men, current smoking also influences this combined phenotype. These factors should be considered in clinical COPD care.

\section{Disclosure}

The authors report no conflicts of interest in this work.

\section{References}

1. Global Initiative for Chronic Obstructive Lung Disease [webpage on the Internet]. Global Strategy for the Diagnosis, Management and Prevention of COPD, Global Initiative for Chronic Obstructive Lung Disease (GOLD) 2015. Available from: http://www.goldcopd.org/. Accessed June 24, 2015.

2. Agusti A, Calverley PM, Celli B, et al; Evaluation of COPD Longitudinally to Identify Predictive Surrogate Endpoints (ECLIPSE) investigators. Characterisation of COPD heterogeneity in the ECLIPSE cohort. Respir Res. 2010;11:122.
3. Kim V, Han MK, Vance GB, et al; COPDGene Investigators. The chronic bronchitic phenotype of COPD: an analysis of the COPDGene Study. Chest. 2011;140(3):626-633.

4. de Oca MM, Halbert RJ, Lopez MV, et al. The chronic bronchitis phenotype in subjects with and without COPD: the PLATINO study. Eur Respir J. 2012;40(1):28-36.

5. Sundh J, Johansson G, Larsson K, et al. Comorbidity and health-related quality of life in patients with severe chronic obstructive pulmonary disease attending Swedish secondary care units. Int J Chron Obstruct Pulmon Dis. 2015;10:173-183.

6. Ekberg-Aronsson M, Pehrsson K, Nilsson JA, Nilsson PM, Löfdahl CG. Mortality in GOLD stages of COPD and its dependence on symptoms of chronic bronchitis. Respir Res. 2005;6:98.

7. Lindberg A, Sawalha S, Hedman L, Larsson LG, Lundbäck B, Rönmark E. Subjects with COPD and productive cough have an increased risk for exacerbations and death. Respir Med. 2015;109(1):88-95.

8. Donaldson GC, Seemungal TA, Bhowmik A, Wedzicha JA. Relationship between exacerbation frequency and lung function decline in chronic obstructive pulmonary disease. Thorax. 2002;57(10):847-852.

9. Wedzicha JA, Seemungal TA. COPD exacerbations: defining their cause and prevention. Lancet. 2007;370(9589):786-796.

10. Oostenbrink JB, Rutten-van Mölken MP. Resource use and risk factors in high-cost exacerbations of COPD. Respir Med. 2004;98(9):883-891.

11. Nishimura K, Sato S, Tsukino M, et al. Effect of exacerbations on health status in subjects with chronic obstructive pulmonary disease. Health Qual Life Outcomes. 2009;7:69.

12. Bourbeau J, Ford G, Zackon H, Pinsky N, Lee J, Ruberto G. Impact on patients' health status following early identification of a COPD exacerbation. Eur Respir J. 2007;30(5):907-913.

13. Groenewegen KH, Schols AM, Wouters EF. Mortality and mortalityrelated factors after hospitalization for acute exacerbation of COPD. Chest. 2003;124(2):459-467.

14. Soler-Cataluña JJ, Martínez-García MA, Román Sánchez P, Salcedo E, Navarro M, Ochando R. Severe acute exacerbations and mortality in patients with chronic obstructive pulmonary disease. Thorax. 2005; 60(11):925-931.

15. Miravitlles M, Soler-Cataluña JJ, Calle M, et al. A new approach to grading and treating COPD based on clinical phenotypes: summary of the Spanish COPD guidelines (GesEPOC). Prim Care Respir J. 2013;22(1):117-121.

16. Pasquale MK, Sun SX, Song F, Hartnett HJ, Stemkowski SA. Impact of exacerbations on health care cost and resource utilization in chronic obstructive pulmonary disease patients with chronic bronchitis from a predominantly Medicare population. Int J Chron Obstruct Pulmon Dis. 2012;7:757-764.

17. Rennard SI, Calverley PM, Goehring UM, Bredenbröker D, Martinez FJ. Reduction of exacerbations by the PDE4 inhibitor roflumilast - the importance of defining different subsets of patients with COPD. Respir Res. 2011;12:18.

18. MartinezFJ, Calverley PM, Goehring UM, Brose M, Fabbri LM, Rabe KF. Effect of roflumilast on exacerbations in patients with severe chronic obstructive pulmonary disease uncontrolled by combination therapy (REACT): a multicentre randomised controlled trial. Lancet. 2015;385(9971):857-866.

19. Sundh J, Ställberg B, Lisspers K, Montgomery SM, Janson C. Comorbidity, body mass index and quality of life in COPD using the Clinical COPD Questionnaire. COPD. 2011;8(3):173-181.

20. Kruis AL, Ställberg B, Jones RC, et al. Primary care COPD patients compared with large pharmaceutically-sponsored COPD studies: an UNLOCK validation study. PLoS One. 2014;9(3):e90145.

21. Seymour JM, Spruit MA, Hopkinson NS, et al. The prevalence of quadriceps weakness in COPD and the relationship with disease severity. Eur Respir J. 2010;36(1):81-88.

22. Maltais F, Decramer M, Casaburi R, et al; ATS/ERS Ad Hoc Committee on Limb Muscle Dysfunction in COPD. An official American Thoracic Society/European Respiratory Society statement: update on limb muscle dysfunction in chronic obstructive pulmonary disease. Am J Respir Crit Care Med. 2014;189(9):e15-e62. 
23. Patel AR, Hurst JR. Extrapulmonary comorbidities in chronic obstructive pulmonary disease: state of the art. Expert Rev Respir Med. 2011; 5(5):647-662.

24. Späte U, Schulze PC. Proinflammatory cytokines and skeletal muscle. Curr Opin Clin Nutr Metab Care. 2004;7(3):265-269.

25. Watz H, Waschki B, Boehme C, Claussen M, Meyer T, Magnussen H. Extrapulmonary effects of chronic obstructive pulmonary disease on physical activity: a cross-sectional study. Am J Respir Crit Care Med. 2008;177(7):743-751.

26. Yende S, Waterer GW, Tolley EA, et al. Inflammatory markers are associated with ventilatory limitation and muscle dysfunction in obstructive lung disease in well functioning elderly subjects. Thorax. 2006;61(1):10-16.

27. Wüst RC, Morse CI, de Haan A, Rittweger J, Jones DA, Degens H. Skeletal muscle properties and fatigue resistance in relation to smoking history. Eur J Appl Physiol. 2008;104(1):103-110.

28. Silverman EK, Weiss ST, Drazen JM, et al. Gender-related differences in severe, early-onset chronic obstructive pulmonary disease. Am J Respir Crit Care Med. 2000;162(6):2152-2158.
29. Van Winkle LS, Gunderson AD, Shimizu JA, Baker GL, Brown CD. Gender differences in naphthalene metabolism and naphthaleneinduced acute lung injury. Am J Physiol Lung Cell Mol Physiol. 2002;282(5):L1122-L1134.

30. Seemungal TA, Donaldson GC, Paul EA, Bestall JC, Jeffries DJ, Wedzicha JA. Effect of exacerbation on quality of life in patients with chronic obstructive pulmonary disease. Am J Respir Crit Care Med. 1998;157(5 Pt 1):1418-1422.

31. Burgel PR, Nesme-Meyer P, Chanez P, et al; Initiatives Bronchopneumopathie Chronique Obstructive Scientific Committee. Cough and sputum production are associated with frequent exacerbations and hospitalizations in COPD subjects. Chest. 2009;135(4):975-982.

32. Herath SC, Poole P. Prophylactic antibiotic therapy for chronic obstructive pulmonary disease (COPD) [review]. Cochrane Database Syst Rev. 2013;11:CD009764.

\section{Publish your work in this journal}

The International Journal of COPD is an international, peer-reviewed journal of therapeutics and pharmacology focusing on concise rapid reporting of clinical studies and reviews in COPD. Special focus is given to the pathophysiological processes underlying the disease, intervention programs, patient focused education, and self management protocols.

\section{Dovepress}

This journal is indexed on PubMed Central, MedLine and CAS. The manuscript management system is completely online and includes a very quick and fair peer-review system, which is all easy to use. Visit $\mathrm{http}: / / \mathrm{www}$.dovepress.com/testimonials.php to read real quotes from published authors. 